\title{
Obesity-Related Policy/Environmental Interventions
}

\section{A Systematic Review of Economic Analyses}

Robin A. McKinnon, PhD, ${ }^{1,2}$ Sameer M. Siddiqi, BA, ${ }^{3}$ Frank J. Chaloupka, PhD,${ }^{4}$ Lisa Mancino, $\mathrm{PhD},{ }^{5}$ Kislaya Prasad, $\mathrm{PhD}^{6}$

From the ${ }^{1}$ Division of Cancer Control and Population Sciences, National Cancer Institute, Bethesda, Maryland; ${ }^{2}$ Center for Food Safety and Applied Nutrition, Food and Drug Administration, College Park, Maryland; ${ }^{3}$ Johns Hopkins Bloomberg School of Public Health, Johns Hopkins University, Baltimore, Maryland; ${ }^{4}$ Health Policy Center Institute for Health Research and Policy, University of Illinois at Chicago, Chicago, Illinois; ${ }^{5}$ U.S. Department of Agriculture, Economic Research Service, Washington, District of Columbia; and ${ }^{6}$ Robert H. Smith School of Business, University of Maryland, College Park, Maryland

Address correspondence to: Robin A. McKinnon, PhD, Center for Food Safety and Applied Nutrition, Food and Drug Administration, 5100 Paint Branch Parkway, College Park MD 20740. E-mail: robin.mckinnon@fda.hhs.gov. 
Context: Policy and environmental changes to support and encourage individual-level nutrition and physical activity behavior are underway in many parts of the U.S. and around the world at national, state, and local levels. Yet, to the authors' knowledge, no summary of the cost-benefit or cost-effectiveness studies of obesity-related policy/environmental interventions exists.

Evidence acquisition: The PRISMA (Preferred Reporting Items for Systematic Reviews and Meta-Analyses) statement guidelines were followed to identify, screen, and describe the protocols used in this systematic review. In 2014, a unique search was conducted of titles and abstracts in MEDLINE, EconLit, SCOPUS, and Web of Science databases that were published from January 2002 through January 2014 in English-language, peer-reviewed journals. The search terms described obesity, physical activity, and diet in combination with economic evaluation.

Evidence synthesis: In 2014 and 2015, the results were analyzed. A total of 27 studies met the inclusion criteria, of which 26 described separate interventions. Of the 27 included studies, eight focused on the community and built environment, seven assessed nutrition-related changes, nine reported on the school environment; and three evaluated social marketing and media interventions. The vast majority of included studies reported beneficial economic outcomes of the interventions.

Conclusions: Given the large and growing literature on the health and behavioral outcomes of policy and environmental interventions, the relatively low number of located benefit-cost and cost-effectiveness economic assessments appears to indicate a prime opportunity for the research community to address. 


\section{Context}

High rates of obesity in the U.S. ${ }^{1}$ are a grave public health concern given the association between high BMI and increased risk of numerous adverse health outcomes, such as increased risk of cardiovascular disease, Type 2 diabetes, and certain forms of cancer. ${ }^{2-6}$ In turn, these health outcomes can lead to significantly increased economic costs related to health care, reduced productivity, and increased disability rates. ${ }^{7-9}$

Policy and environmental changes to support and encourage individual-level nutrition and physical activity behavior are underway in many parts of the U.S. and around the world at national, state, and local levels, including: changes to food environments; transportation systems, urban planning, and parks and recreation; information environments; youth settings, such as childcare and schools; and healthcare and clinical settings. Examples of those policy and environmental changes include increasing access to healthy food in underserved areas, supporting complete streets initiatives and mixed use zoning, menu labeling and media campaigns, and changing school food and physical education requirements. ${ }^{10-16}$

Cost-benefit and cost-effectiveness assessments of obesity-related policy/environmental interventions can play a critical role by helping policymakers assess options to support and improve nutrition and physical activity behavior, particularly in resource-constrained environments. At the federal level, cost-benefit and cost-effectiveness analyses are the primary tools used to justify changes in existing policies and creation of new regulations by showing whether benefits from a proposed action outweigh the costs and whether the proposed action is the most efficient option. ${ }^{17}$ Federal agencies are also encouraged to make use of evidence-based 
strategies and cost-effectiveness data to improve resource allocation. Findings from such evaluations have informed the development of policy and other interventions to reduce tobacco and alcohol use and to enhance road safety. ${ }^{18-20}$ Many studies and reviews have been published on the direct (e.g., health care) and indirect (e.g., absenteeism) costs of obesity. ${ }^{7-9,21-24}$ There is also a large literature on health and behavioral outcomes associated with policy and environmental interventions, ${ }^{11-13}$ and one review assessed cost of illness and cost effectiveness of childhood obesity interventions, ${ }^{25}$ but to the authors' knowledge no summary of the costbenefit or cost-effectiveness studies of obesity-related policy/environmental interventions for youth and the general population exists. The present study seeks to fill that gap.

Economic evaluations have been particularly informative for the development and implementation of policy and environmental interventions to reduce tobacco use. Based on the experiences with comprehensive state tobacco programs which have been demonstrated to be highly cost effective, ${ }^{26} \mathrm{CDC}$ has developed and refined recommendations for "best practices" for these programs. ${ }^{27}$

A note on terminology: Cost-benefit (also referred to as benefit-cost) analysis is an attempt to identify the societal costs and benefits over time that are associated with a course of action, assign monetary values to those costs and benefits, and determine the net costs/benefits in monetary terms in today's dollars, that is, the net present value. ${ }^{28}$ By contrast, cost-effectiveness analysis (also sometimes called cost-utility analysis) assesses relative costs and effects of two or more different options, and often expresses those outcomes in terms of quality- or disabilityadjusted life-years (QALYs or DALYs) or healthy years equivalents (HYEs) in an attempt to 
account for gains in quality of life. ${ }^{28}$ In recent years, the quality-adjusted life-year has become the preferred measure given that it reflects the benefits of both reductions in morbidity and mortality in a way that is more consistent with economic theory. In addition, the incremental cost-effectiveness ratio (ICER) expressed as incremental time discounted dollar costs per discounted quality-adjusted life-year gained, is used for comparisons of alternative policies, and compared against standard benchmarks to determine if the policy is cost effective.

Applying cost-benefit and cost-effectiveness methodology to the assessment of obesity-related policy and environmental interventions can be challenging, primarily because of the time horizon over which the costs and benefits of a policy or environmental change accrue. An intervention may result in direct effects (such as behavior modification), which in turn may have effects over a longer time horizon (such as reduced risk for chronic disease). There is a long and complex pathway from diet and activity changes to improvements in life expectancy and quality. Often only the direct effects and some subset of indirect effects (e.g., BMI changes) are observed over the duration of the typical study from which parameters for economic assessments are extracted. Some parameters are estimated from carefully designed studies, others are derived from the published literature (frequently using best available, but imperfect measures), and some parameter values are chosen by assumption. Nevertheless, results from these economic assessment studies may provide helpful input to decision makers.

\section{Evidence Acquisition}

The PRISMA (Preferred Reporting Items for Systematic Reviews and Meta-Analyses) statement guidelines were followed to identify, screen, and describe the protocols used in this systematic 
review. ${ }^{29}$ A unique search of titles and abstracts in MEDLINE, EconLit, SCOPUS, and Web of Science databases that were published from January 2002 through January 2014 was conducted. Additional studies as references in related reviews were also included. The search was limited to English-language articles that were published in peer-reviewed journals. The search terms, which describe obesity, physical activity, and diet in combination with economic evaluation, were cross-searched using the following algorithm: (obes*, weight, BMI, bariatric, physical activity, exercise, diet, nutrition, food) AND (cost analysis, cost effective*, cost utility, cost benefit,

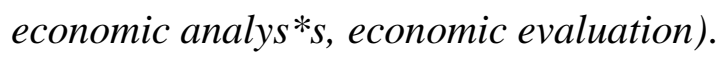

After duplicates were removed, the titles and abstracts of the search results were screened by two authors (SS and RM) to determine their eligibility (Figure 1). Studies were eligible for inclusion in this review if they reported results from a cost-benefit or cost-effectiveness assessment of a policy or environmental intervention related to diet, physical activity, or obesity that was implemented or implementable by policymakers, and that was also a major component of the published article. All studies selected for inclusion, and a randomly selected subset of excluded studies was reviewed by all co-authors. All studies that met the inclusion criteria, regardless of the sample size, were included.

Excluded were studies that focused on: diet or physical activity outside the context of energy balance/obesity; chronic diseases or conditions related to energy balance/obesity, such as Type 2 diabetes; cost estimation (e.g., costs of health care related to obesity); surgical or pharmacologic therapies; commentaries, reviews, or editorials; and articles that reported only pilot data or descriptions of the design of a study. Finally, articles assessing economic evaluations of an 
intervention that was not a policy or environmental change-for example, individual or group weight loss counseling interventions—-were also excluded.

Relevant study characteristics were abstracted for 270 studies, including study design, intervention design, setting and population, and economic analysis methods, each of which was independently reviewed and verified by at least two authors. To ensure consistency, the abstraction process was conducted through an electronic form with definitions for each variable. Summary statistics and tables were prepared from the resulting data. The 270 abstracted studies were then assessed for eligibility.

\section{Evidence Synthesis}

As shown in Appendix Table 1, a total of 27 studies $^{30-56}$ met the inclusion criteria, of which 26 described separate interventions; two articles ${ }^{53,54}$ presented results on the same intervention. Of the 27 included studies, eight studies ${ }^{34,37-39,43,51,53,54}$ focused on the community and built environment; seven studies ${ }^{30,31,33,36,48-50}$ assessed on nutrition-related policy/education changes, of which five studies ${ }^{31,33,36,48,50}$ analyzed state implementations of the U.S. Expanded Food and Nutrition Education Program (EFNEP); nine studies ${ }^{32,41,42,44-46,52,55,56}$ focused on school environments; and three studies ${ }^{35,40,47}$ evaluated social marketing and media interventions.

Most (15 of 27) studies $32,34,35,37-39,41-43,46,51,53-56$ analyzed policy or environmental changes at the local level, six studies s1,33,36,47,48,50 at the state level, and seven studies $^{30,40,44-46,49,52}$ at the national level. Note that the number of studies does not sum to 27 as one study analyzed an intervention at more than one level of government. ${ }^{46}$ 
Twelve studies ${ }^{34,35,37-39,43-45,47,51,53,54}$ analyzed interventions intended to improve physical activity behavior, nine studies $30,31,33,36,40,48-50,52$ focused on improving diet, and six studies ${ }^{32,41,42,46,55,56}$ assessed interventions addressing both diet and activity. Additionally, 11 studies $^{32,40-42,44-}$ 47,52,55,56 focused on policy and environmental interventions targeting youth; the rest of the studies focused on the general population or adults.

With regard to reported results and economic assessment methods used, all but two studies ${ }^{44,45}$ found that the interventions they assessed were economically beneficial. Fourteen of the studies $^{30,34,35,40-42,44-47,49,52,53,55}$ assessed an intervention's cost effectiveness, nine studies $^{31,33,38,39,43,48,50,51,54}$ conducted cost-benefit analysis, and four studies ${ }^{32,36,37,56}$ assessed both the cost effectiveness and the cost benefit of an intervention.

Included studies varied considerably by the design of the policy or environmental intervention being assessed for economic effects. Most (14 of 27) papers ${ }^{31,33-37,41,43,46,48,50,52,53,54}$ were economic assessments of policy or environmental changes using quasi-experimental designs usually natural experiments, that is, policy or environmental changes outside the direct control of researchers. Nine studies ${ }^{30,38,39,40,44,45,47,49,51}$ used secondary data analysis to determine their economic assessments Four studies ${ }^{32,42,55,56}$ assessed economic results of RCTs, and two studies $^{40,49}$ assessed effects of hypothetical policy interventions. Nine studies $30,35,37,40,44-46,51,49$ used simulation modeling techniques in their economic assessments.

\section{Discussion}


Perhaps the most striking finding from the review presented here is the relative paucity of studies located conducting cost-benefit or cost-effectiveness assessments of obesity-related policy and environmental interventions in the published literature. Given the large and growing literature on the health and behavioral outcomes of those interventions, the relative lack of associated economic assessments is surprising and represents a prime opportunity for researchers to address.

Another key finding from this present analysis is that the vast majority of included studies reported beneficial economic outcomes, which may be helpful information for policymakers considering similar interventions. Of course, this finding may also be a product of publication bias. Nevertheless, some studies were published that did not find beneficial effects.

The methodologic designs of the interventions described in studies included in the present review also varied considerably, using RCTs, quasi-experimental designs, primary and secondary data analysis, and simulations, demonstrating the innovation by researchers from a variety of fields to assess the interventions. The variety of methods is not surprising given that policy and environmental changes that may improve population diet or physical activity are rarely under the direct control of researchers.

The papers included in this review take two primary approaches to the assessment of interventions:

1. making the best possible assumptions about the parameters then proceeding with the economic analysis; and 
2. taking a narrower view by considering a more restricted time horizon, over which uncertainty is reduced.

Given the uncertainty regarding some key parameters, and the trade-off between exhaustiveness and precision in measurement, it is hard to recommend one approach over the other. Both types of studies are desirable as they add to the body of knowledge about the effectiveness of obesityrelated policy in different and complementary ways. A key gap for future studies to address would be the long-run effects of interventions on health. Even medium-term studies on the extent to which any intervention changes persist would provide valuable insights for future economic analyses.

At least in the U.S., challenges often exist to increased collaboration between public health researchers and economists, in spite of the many potential benefits to research and practice. For instance, unlike public health researchers, many or most economists in traditional schools of economics are funded by "hard money," that is, these positions are salaried and do not require grant or outside funding, and multiple authorship of papers is often frowned upon in traditional economic circles. Additionally, economists often communicate in a language that is difficult, at best, for non-economists to understand. Another difference may be that public health researchers tend to design studies to assess health outcomes whereas economists are more likely to design studies that assess economic efficiency.

Increasing collaboration between public health researchers and economists would likely benefit the research community broadly and yield valuable information for decision makers at federal, 
state, and local levels. Some suggestions for public health researchers to increase collaboration with economists include:

1. approaching economics colleagues in their initial stages of research study planning and development, rather than (sometimes much) later in the process when critical economic data may be hard or impossible to collect;

2. highlighting the potential for broad impact of study findings with their economics colleagues;

3. approaching health economists in schools of public health as potential collaborators; and

4. offering economic training in schools of public health, in order to better understand the language and foundational concepts of their economics colleagues.

\section{Limitations}

This review is limited in several ways. First, the search criteria used in the present review may not have located all of the relevant studies. Second, the located studies may be the result of publication bias against null findings. Third, because the rise in childhood obesity is relatively recent, only now is its impact on morbidity and mortality in later life beginning to be seen. As such, it is difficult to know precisely the costs and benefits associated with interventions to address childhood obesity.

\section{Conclusions}

Despite these limitations, the review presented here appears to fill an important gap in the literature. For many policymakers and decision makers, economic assessments of the 
interventions under consideration to improve nutrition, physical activity, and obesity may be informative when considering options to pursue.

In addition to public health practitioners, there appears to be a growing interest among many non-traditional public health partners in incorporating health-related concerns into future plans. Cost-benefit and cost-effectiveness assessments of both health and related outcomes would be helpful additional considerations for these audiences, and help guide future interventions to improve the health and well-being of all Americans. 


\section{Acknowledgments}

The authors are grateful to Penny Randall-Levy for expert referencing support. Funding for

Frank J. Chaloupka's time was supported by the Robert Wood Johnson Foundation's grant to the University of Illinois at Chicago for the Bridging the Gap program.

The opinions and conclusions expressed in this article are solely the views of the authors and do not necessarily reflect those of the Food and Drug Administration.

No financial disclosures were reported by the authors of this paper. 


\section{References}

1. Ogden CL, Carroll MD, Kit BK, Flegal KM. Prevalence of childhood and adult obesity in the United States, 2011-2012. JAMA. 2014;311(8):806-814. http://dx.doi.org/10.1001/jama.2014.732.

2. Ogden CL, Yanovski SZ, Carroll MD, Flegal KM. The epidemiology of obesity. Gastroenterology. 2007;132(6):2087-2102. http://dx.doi.org/10.1053/j.gastro.2007.03.052.

3. Menke A, Rust KF, Fradkin J, Cheng YJ, Cowie CC. Associations between trends in race/ethnicity, aging, and body mass index with diabetes prevalence in the United States: a series of cross-sectional studies. Ann Intern Med. 2014;161(5):328-335. http://dx.doi.org/10.7326/M14-0286.

4. Cheng YJ, Imperatore G, Geiss LS, et al. Secular changes in the age-specific prevalence of diabetes among U.S. adults: 1988-2010. Diabetes Care. 2013;36(9):2690-2696. http://dx.doi.org/10.2337/dc12-2074.

5. Van Gaal LF, Mertens IL, De Block CE. Mechanisms linking obesity with cardiovascular disease. Nature. 2006;444(7121):875-880. http://dx.doi.org/10.1038/nature05487.

6. Renehan AG, Tyson M, Egger M, Heller RF, Zwahlen M. Body-mass index and incidence of cancer: a systematic review and meta-analysis of prospective observational studies. Lancet. 2008;371(9612):569-578. http://dx.doi.org/10.1016/S01406736(08)60269-X.

7. Hammond RA, Levine R. The economic impact of obesity in the United States. Diabetes Metab Syndr Obes. 2010;3:285-295. http://dx.doi.org/10.2147/DMSOTT.S7384. 
8. Trogdon JG, Finkelstein EA, Hylands T, Dellea PS, Kamal-Bahl SJ. Indirect costs of obesity: a review of the current literature. Obes Rev. 2008;9(5):489-500. http://dx.doi.org/10.1111/j.1467-789X.2008.00472.x.

9. Tsai AG, Williamson DF, Glick HA. Direct medical cost of overweight and obesity in the USA: a quantitative systematic review. Obes Rev. 2011;12(1):50-61. http://dx.doi.org/10.1111/j.1467-789X.2009.00708.x.

10. McKinnon RA, Orleans CT, Kumanyika SK, et al. Considerations for an obesity policy research agenda. Am J Prev Med. 2009;36(4):351-357. http://dx.doi.org/10.1016/j.amepre.2008.11.017.

11. Brownson RC, Haire-Joshu D, Luke DA. Shaping the context of health: a review of environmental and policy approaches in the prevention of chronic diseases. Annu Rev Public Health. 2006;27:341-370. http://dx.doi.org/10.1146/annurev.publhealth.27.021405.102137.

12. Ding D, Sallis JF, Kerr J, Lee S, Rosenberg DE. Neighborhood environment and physical activity among youth: a review. Am J Prev Med. 2011;41(4):442-455. http://dx.doi.org/10.1016/j.amepre.2011.06.036.

13. Brennan LK, Brownson RC, Orleans CT. Childhood obesity policy research and practice: evidence for policy and environmental strategies. Am J Prev Med. 2014;46(1):e1-16. http://dx.doi.org/10.1016/j.amepre.2013.08.022.

14. Story M, Kaphingst KM, Robinson-O'Brien R, Glanz K. Creating healthy food and eating environments: policy and environmental approaches. Annu Rev Public Health. 2008;29:253-272. http://dx.doi.org/10.1146/annurev.publhealth.29.020907.090926. 
15. Committee on Accelerating Progress in Obesity Prevention, Food and Nutrition Board, Institute of Medicine. Accelerating progress in obesity prevention: solving the weight of the Nation. Washington: The National Academies Press; 2012.

16. Community Preventive Services Task Force. Guide to Community Preventive Services. Environmental and policy approaches to increase physical activity: community-scale urban design land use policies. CDC. www.thecommunityguide.org/pa/environmentalpolicy/communitypolicies.html. Published 2004. Accessed April 13, 2015.

17. Office of Management and Budget. Circular A-4. Subject: regulatory analysis. Office of Management and Budget. www.whitehouse.gov/omb/circulars_a004_a-4/. Published 2003. Accessed April 13, 2015.

18. Ranson MK, Jha P, Chaloupka FJ, Nguyen SN. Global and regional estimates of the effectiveness and cost-effectiveness of price increases and other tobacco control policies. Nicotine Tob Res. 2002;4(3):311-319. http://dx.doi.org/10.1080/14622200210141000.

19. Osterberg E. What are the most effective and cost-effective interventions in alcohol control? WHO Regional Office for Europe. www.euro.who.int/_data/assets/pdf_file/0020/74702/E82969.pdf. Published 2004. Accessed March 16, 2015.

20. Chisholm D, Naci H. Road traffic injury prevention: an assessment of risk exposure and intervention cost-effectiveness in different world regions. WHO. www.who.int/choice/publications/d_2009_road_traffic.pdf?ua=1. Published 2008. Accessed March 16, 2015. 
21. Thorpe KE, Florence CS, Howard DH, Joski P. The impact of obesity on rising medical spending. Health Aff (Millwood). 2004;Suppl Web Exclusives:W4-W6. http://dx.doi.org/10.1377/hlthaff.w4.480.

22. Cawley J, Meyerhoefer C. The medical care costs of obesity: an instrumental variables approach. J Health Econ. 2012;31(1):219-230. http://dx.doi.org/10.1016/j.jhealeco.2011.10.003.

23. Finkelstein E, Fiebelkorn 1, Wang G. The costs of obesity among full-time employees. Am J Health Promot. 2005;20(1):45-51. http://dx.doi.org/10.4278/0890-1171-20.1.45.

24. Finkelstein EA, Trogdon JG, Cohen JW, Dietz W. Annual medical spending attributable to obesity: payer-and service-specific estimates. Health Aff (Millwood). 2009;28(5):w822-w831. http://dx.doi.org/10.1377/hlthaff.28.5.w822.

25. John J, Wolfenstetter SB, Wenig CM. An economic perspective on childhood obesity: recent findings on cost of illness and cost effectiveness of interventions. Nutrition. 2012;28(9):829-839. http://dx.doi.org/10.1016/j.nut.2011.11.016.

26. Max W, Sung HY, Lightwood J. The impact of changes in tobacco control funding on healthcare expenditures in California, 2012-2016. Tob Control. 2013;22(e1):e10-e15. http://dx.doi.org/10.1136/tobaccocontrol-2011-050130.

27. CDC. Best practices for comprehensive tobacco control programs -- 2014. CDC, National Center for Chronic Disease Prevention and Health Promotion, Office on Smoking and Health. www.cdc.gov/tobacco/stateandcommunity/best_practices/pdfs/2014/comprehensive.pdf. Published 2014. Accessed March 16, 2015. 
28. Boardman AE, Greenberg DH, Vining AR, Weimer DL. Cost-benefit analysis: concepts and practice. Upper Saddle River, NJ: Prentice Hall, 2011.

29. Liberati A, Altman DG, Tetzlaff J, et al. The PRISMA statement for reporting systematic reviews and meta-analyses of studies that evaluate health care interventions: explanation and elaboration. J Clin Epidemiol. 2009;62(10):e1-34.

http://dx.doi.org/10.1016/j.jclinepi.2009.06.006.

30. Basu S, Seligman H, Bhattacharya J. Nutritional policy changes in the Supplemental Nutrition Assistance Program: a microsimulation and cost-effectiveness analysis. Med Decis Making. 2013;33(7):937-948. http://dx.doi.org/10.1177/0272989X13493971.

31. Block Joy A, Goldman G, Pradhan V. Cost-benefit analysis conducted for nutrition education in California. Calif Agric (Berkeley). 2006;60(4):185-191. http://dx.doi.org/10.3733/ca.v060n04p185.

32. Brown HS, III, Perez A, Li YP, Hoelscher DM, Kelder SH, Rivera R. The costeffectiveness of a school-based overweight program. Int J Behav Nutr Phys Act. 2007;4:47. http://dx.doi.org/10.1186/1479-5868-4-47.

33. Burney J, Haughton B. EFNEP: a nutrition education program that demonstrates costbenefit. J Am Diet Assoc. 2002;102(1):39-45. http://dx.doi.org/10.1016/S00028223(02)90014-3.

34. Cohen DA, Marsh T, Williamson S, Golinelli D, McKenzie TL. Impact and costeffectiveness of family Fitness Zones: a natural experiment in urban public parks. Health Place. 2012;18(1):39-45. http://dx.doi.org/10.1016/j.healthplace.2011.09.008. 
35. De Smedt D, De Cocker K, Annemans L, De Bourdeaudhuij I, Cardon G. A costeffectiveness study of the community-based intervention '10 000 Steps Ghent'. Public Health Nutr. 2012;15(3):442-451. http://dx.doi.org/10.1017/S1368980011001716.

36. Dollahite J, Kenkel D, Thompson CS. An economic evaluation of the expanded food and nutrition education program. J Nutr Educ Behav. 2008;40(3):134-143. http://dx.doi.org/10.1016/j.jneb.2007.08.011.

37. Frew EJ, Bhatti M, Win K, et al. Cost-effectiveness of a community-based physical activity programme for adults (Be Active) in the UK: an economic analysis within a natural experiment. Br J Sports Med. 2014;48(3):207-212. http://dx.doi.org/10.1136/bjsports-2012-091202.

38. Gotschi T. Costs and benefits of bicycling investments in Portland, Oregon. J Phys Act Health. 2011;8(Suppl 1):S49-S58.

39. Guo JY, Gandavarapu S. An economic evaluation of health-promotive built environment changes. Prev Med. 2010;50(Suppl 1):S44-S49. http://dx.doi.org/10.1016/j.ypmed.2009.08.019.

40. Magnus A, Haby MM, Carter R, Swinburn B. The cost-effectiveness of removing television advertising of high-fat and/or high-sugar food and beverages to Australian children. Int J Obes (Lond). 2009;33(10):1094-1102. http://dx.doi.org/10.1038/ijo.2009.156.

41. McAuley KA, Taylor RW, Farmer VL, et al. Economic evaluation of a community-based obesity prevention program in children: the APPLE project. Obesity (Silver Spring). 2010;18(1):131-136. http://dx.doi.org/10.1038/oby.2009.148. 
42. Meng L, Xu H, Liu A, et al. The costs and cost-effectiveness of a school-based comprehensive intervention study on childhood obesity in China. PLoS One. 2013;8(10):e77971. http://dx.doi.org/10.1371/journal.pone.0077971.

43. Montes F, Sarmiento OL, Zarama R, et al. Do health benefits outweigh the costs of mass recreational programs? An economic analysis of four Ciclovia programs. J Urban Health. 2012;89(1):153-170. http://dx.doi.org/10.1007/s11524-011-9628-8.

44. Moodie M, Haby M, Galvin L, Swinburn B, Carter R. Cost-effectiveness of active transport for primary school children - Walking School Bus program. Int J Behav Nutr Phys Act. 2009;6:63. http://dx.doi.org/10.1186/1479-5868-6-63.

45. Moodie ML, Carter RC, Swinburn BA, Haby MM. The cost-effectiveness of Australia's Active After-School Communities program. Obesity (Silver Spring). 2010;18(8):15851592. http://dx.doi.org/10.1038/oby.2009.401.

46. Moodie ML, Herbert JK, de Silva-Sanigorski AM, et al. The cost-effectiveness of a successful community-based obesity prevention program: the Be Active Eat Well program. Obesity (Silver Spring). 2013;21(10):2072-2080. http://dx.doi.org/10.1002/oby.20472.

47. Peterson M, Chandlee M, Abraham A. Cost-effectiveness analysis of a statewide media campaign to promote adolescent physical activity. Health Promot Pract. 2008;9(4):426433. http://dx.doi.org/10.1177/1524839907313722.

48. Rajgopal R, Cox RH, Lambur M, Lewis EC. Cost-benefit analysis indicates the positive economic benefits of the Expanded Food and Nutrition Education Program related to chronic disease prevention. J Nutr Educ Behav. 2002;34(1):26-37. http://dx.doi.org/10.1016/S1499-4046(06)60225-X. 
49. Sacks G, Veerman JL, Moodie M, Swinburn B. 'Traffic-light' nutrition labelling and 'junk-food' tax: a modelled comparison of cost-effectiveness for obesity prevention. Int $J$ Obes (Lond). 2011;35(7):1001-1009. http://dx.doi.org/10.1038/ijo.2010.228.

50. Schuster E, Zimmerman ZL, Engle M, Smiley J, Syversen E, Murray J. Investing in Oregon's Expanded Food and Nutrition Education Program (EFNEP): documenting costs and benefits. J Nutr Educ Behav. 2003;35(4):200-206. http://dx.doi.org/10.1016/S14994046(06)60334-5

51. Stokes RJ, MacDonald J, Ridgeway G. Estimating the effects of light rail transit on health care costs. Health Place. 2008;14(1):45-58. http://dx.doi.org/10.1016/j.healthplace.2007.04.002.

52. te Velde SJ, Lennert Veerman J, Tak NI, Bosmans JE, Klepp KI, Brug J. Modeling the long term health outcomes and cost-effectiveness of two interventions promoting fruit and vegetable intake among schoolchildren. Econ Hum Biol. 2011;9(1):14-22. http://dx.doi.org/10.1016/j.ehb.2010.09.001.

53. Wang G, Macera CA, Scudder-Soucie B, Schmid T, Pratt M, Buchner D. Cost effectiveness of a bicycle/pedestrian trail development in health promotion. Prev Med. 2004;38(2):237-242. http://dx.doi.org/10.1016/j.ypmed.2003.10.002.

54. Wang G, Macera CA, Scudder-Soucie B, Schmid T, Pratt M, Buchner D. A cost-benefit analysis of physical activity using bike/pedestrian trails. Health Promot Pract. 2005;6(2):174-179. http://dx.doi.org/10.1177/1524839903260687.

55. Wang LY, Gutin B, Barbeau P, et al. Cost-effectiveness of a school-based obesity prevention program. $J$ Sch Health. 2008;78(12):619-624. http://dx.doi.org/10.1111/j.1746-1561.2008.00357.x. 
56. Wang LY, Yang Q, Lowry R, Wechsler H. Economic analysis of a school-based obesity prevention program. Obes Res. 2003;11(11):1313-1324. http://dx.doi.org/10.1038/oby.2003.178. 


\section{List of Figures}

Figure 1. Flowchart of search, screening and selection process. 

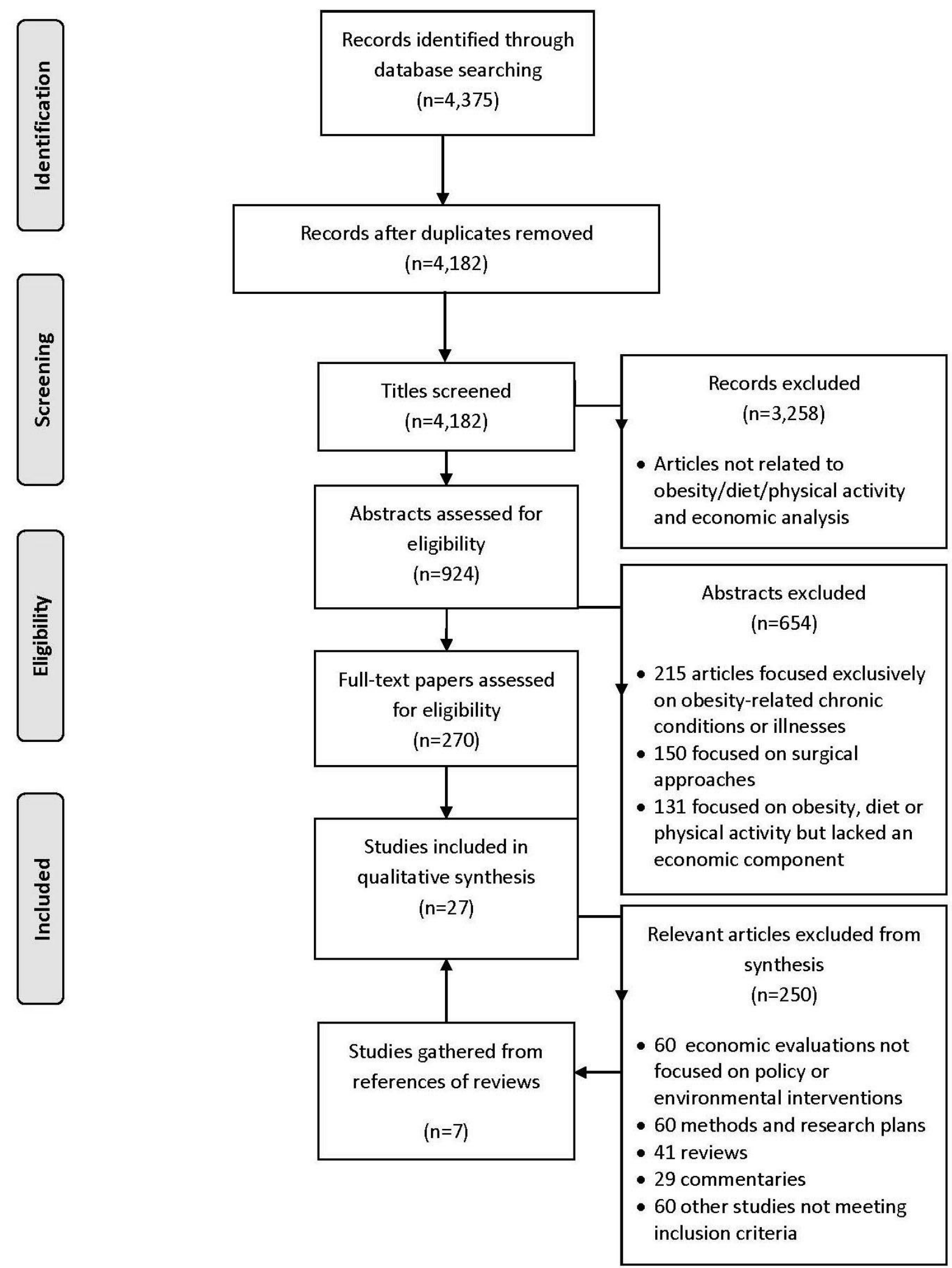